\title{
Sealed Environmental Cell Microscopy
}

Hiromi Konishi*, Akira Ishikawa**, Ying-Bing Jiang*, Peter Buseck***, Huifang Xu*

*Dept. of Earth and Planetary Sciences, The University of New Mexico, Albuquerque NM 87131

**Dept. of Physics, Nihon University, Sakurajosui, Setagaya-Ku, Tokyo 156, Japan

***Depts. of Geological Sciences and Chemistry/Biochemistry, Arizona State University, Tempe, AZ 85287

To control the environment inside transmission electron microscope (TEM) is very desirable to study dynamic interactions between liquid and solid. Current environmental cells can be divided into two categories, apertured and windowed, depending on the method of containing an aqueous or gaseous media. Both types of environmental cells need a special pumping system or extensive modification of a regular electron microscope. Here, we preliminary report an environmental cell technique in which two thin-film windows simply seal space around specimens. We distinguish such simple sealed capsules from the windowed cells and call them sealed cells. Sealed cells have some advantages, although it is impossible to inject liquid or gas into the cells. First, it is more convenient for observing specimens at wet conditions than the other types of environmental cells. It is easy to modify a TEM holder and TEM for a sealed cell. Second, it allows us to look at specimens at atmospheric pressure, extending capability of windowed environmental cell technique. Third, it allows us to design a reaction chamber that is removable from a TEM holder.

Carbon film for windows of sealed cells must be thin enough to permit electron penetration and also sustain the pressure difference between the vacuum of the TEM and the sealed cell. To reduce inelastic scattering of windows, we tried to minimize thickness of carbon film. We made carbon with some thicknesses using vacuum deposition techniques at $10^{-6}$ Torr range and determined an optimal thickness. In the case of the films with 100 - $\mu \mathrm{m}$ diameters, most have a pressure resistance above atmospheric pressure, and $\sim 15-\mathrm{nm}$ thick carbon film can be used as window material of sealed cell (Fig. 1).

To reduce inelastic scattering of gas around specimens we also need to minimize the gas-filled gap in sealed cell. We measured electron transmittance of air saturated by water using a windowed environmental cell. A 150- $\mu \mathrm{m}$ objective aperture was used. Electron transmittance of air sandwiched by $22-\mathrm{nm}$ carbon films exponentially decreases with the pressure within the cell. Where the gas-filled gaps between two 22-nm carbon films are 50, 150, 250 and $500 \mu \mathrm{m}$ in thickness, the electron transmittance decreased from $92 \%$ in vacuum to $82,75,65$ and $40 \%$ at 760 Torr, respectively.

Several sealed cells were designed and tested. The cells are sealed from the vacuum using either external or internal gaskets (Fig. 2). To avoid a sudden change of pressure outside the cell when it is brought into a TEM column, we insert a needle valve and a vacuum gage between a chamber for exchanging holder and a rotary pump (between V8 and V10 for JEM 2000FX and EX; between V21 and V12 for JEM 2010). We modified a windowed environmental cell holder designed by Fukami [1] into a sealed cell and tested it. The cell achieves $50-\mu \mathrm{m}$ thickness of the gas-filled gap. Sealed cells were also made using an internal gasket for a tilt-rotation holder (JEOL EM-SRH10) and a double-tilt holder (GATAN EM20). This type of cell consists of an gasket (O-ring; 2.8, 2.6 
$\mathrm{mm}$ in outer and inner diameter, respectively, for JEOL EM-SRH10, disk; 2.9, $2.0 \mathrm{~mm}$ and the thickness $100 \mu \mathrm{m}$ for GATAN EM20) and two bronze grids sealed by $\mathrm{C}$ film $(3.5 \mathrm{~mm}$ in diameter and $100 \mu \mathrm{m}$ thick for JEOL EM-SRH10 and $3.0 \mathrm{~mm}$ in diameter and $50 \mu \mathrm{m}$ thick for GATAN EM20 and $100 \mu \mathrm{m}$ in thickness). They have 7, 9 or 19 holes. The O-ring seals the end of the cell from the vacuum and also plays the role of a spacer. To make a gas-filled gap less than $100 \mu \mathrm{m}$ in thickness was impossible for this type of cell. Small capsules that are removable from a TEM holder were also designed. Sealed cells were able to keep moisture condition within the cell. Water trapped in sealed cells were observed after the cells were left in the column for about 24 hours, which was the outer duration of the experiments (Fig. 3). The lattice fringe of graphite $(0.34 \mathrm{~nm})$ was recorded. Using sealed cells we observed swelling of clay minerals and other reactions in solutions.

\section{Reference}

[1] Fukami A, Fukushima K, Kohyama N (1991) Observation technique for wet clay minerals using film-sealed environmental cell equipment attached to high-resolution electron microscope. In:

Microstructure of fine grained sediments; from mud to shale, Bennett RH, Bryant WR, Hulbert MH (eds). New York: Springer, pp 321-331

Fig. 1. Schematic drawings of sealed cells. A: grid, B: spacer, C and D: gasket, E: cap, F: annular plug, G: sealing block, H: screw, a: grid, b: O-ring, c: hex ring.

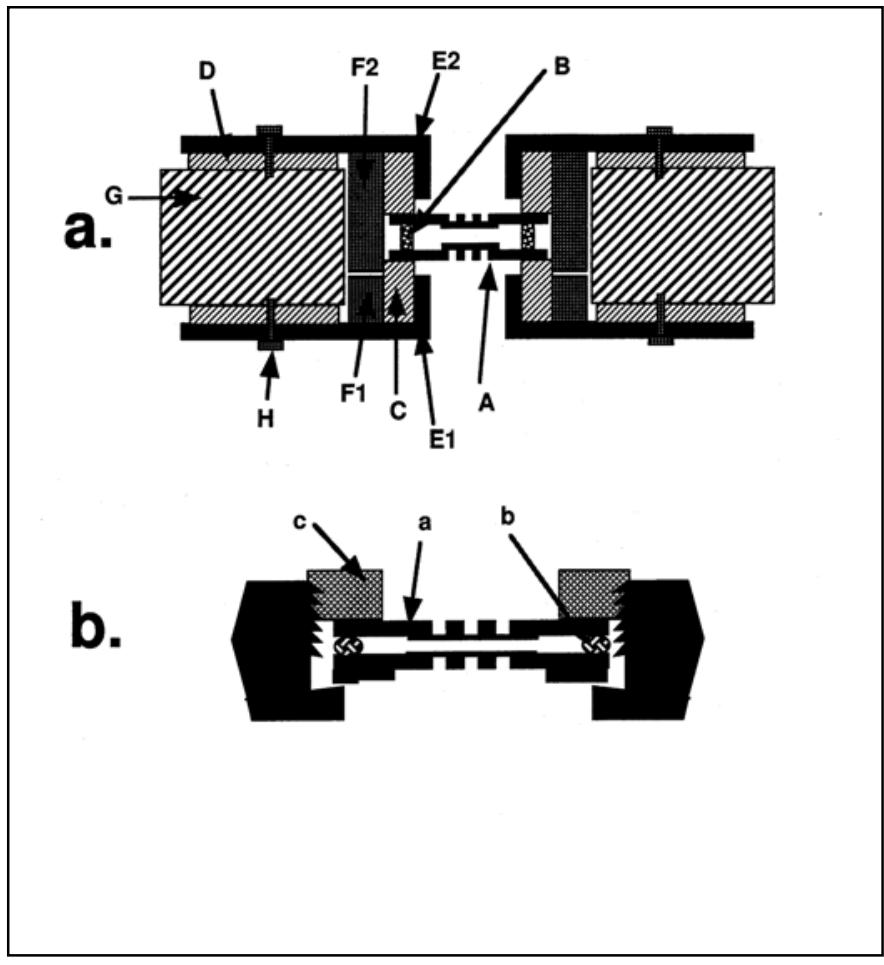

Fig. 2. Pressure resistance of carbon films of $100 \mu \mathrm{m}$ in diameter.

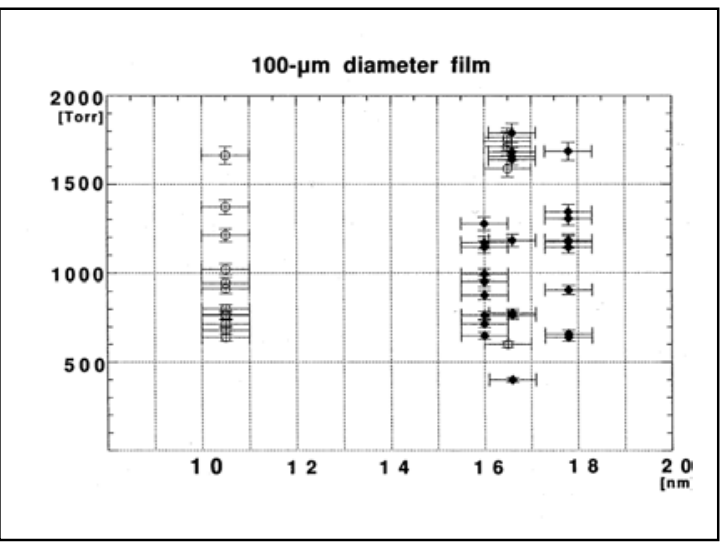

Fig. 3. TEM image of water.

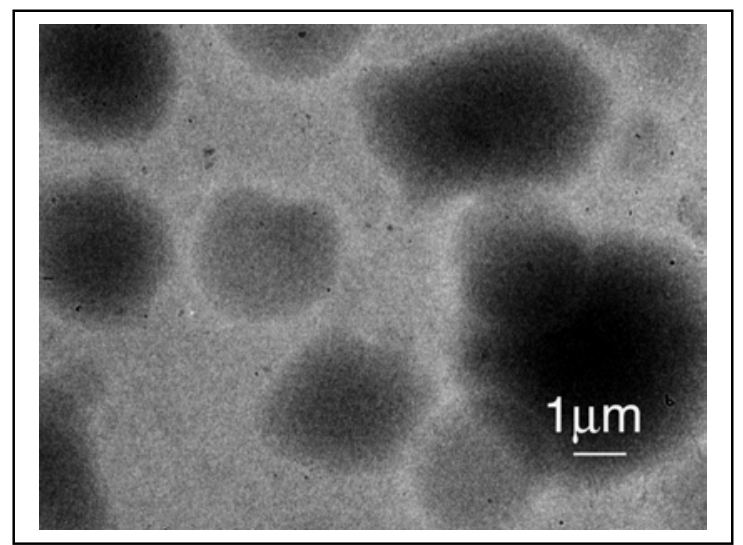

